\title{
Facial markings in the hover wasps: quality signals and familiar recognition cues in two species of Stenogastrinae
}

\author{
D. Baracchi ${ }^{\text {a,* }}$, I. Petrocelli ${ }^{\text {a }}$, G. Cusseau ${ }^{\text {a }}$, L. Pizzocaro ${ }^{\text {a }}$, S. Teseo ${ }^{\text {b }}$, S. Turillazzi ${ }^{\text {a }}$ \\ a Università degli Studi di Firenze, Dipartimento di Biologia Evoluzionistica 'Leo Pardi', Firenze, Italy \\ ${ }^{\mathrm{b}}$ Université Paris 13, Laboratoire d'Ethologie Expérimentale et Comparée, EA 4443, Paris, France
}

\section{A R T I C L E I N F O}

Article history:

Received 28 June 2012

Initial acceptance 23 July 2012

Final acceptance 9 October 2012

Available online 21 November 2012

MS. number: 12-00501R

\section{Keywords:}

animal communication

badge of status

conventional signal

dominance hierarchy

hover wasp

Liostenogaster flavolineata

Liostenogaster vechti

quality signal

recognition system

social behaviour
Both recognition and conventional signals are widespread in the animal kingdom. Chemical communication plays a major role in invertebrates, and especially in social insects. In the last decade, observational and experimental evidence has shown the existence of visual quality signals and individual recognition cues in Polistes paper wasps, meaning that visual communication might also be common in insect societies. Here we show that two species of facultatively eusocial hover wasps (Vespidae, Stenogastrinae) use the visual channel for social communication. By combining morphoanatomical measurements and behavioural assays, we found that the size of the dark facial markings was related to reproductive status and dominance in colonies of Liostenogaster vechti, thus representing a badge of status. By contrast, no correlation between facial coloration and reproductive status was found in Liostenogaster flavolineata, which instead used facial markings as familiar visual recognition cues. Our results reveal that visual communication in social insects might be more widespread than previously thought and has evolved independently in distinct wasp taxa facing similar selection pressures.

(c) 2012 The Association for the Study of Animal Behaviour. Published by Elsevier Ltd. All rights reserved.
Members of animal societies need to cooperate and coordinate group behaviours. Efficient communication systems as well as recognition abilities are required for almost all social behaviours. Nestmate recognition, that is, the ability of an individual to recognize its colony mates, is critical to prevent outsiders from exploiting colony resources (Hölldobler \& Wilson 1990). Discriminating between different colony mates allows individuals to adjust their behaviours, which is fundamental for assessing and maintaining dominance hierarchies and regulating parent-offspring interactions. Most social species can discriminate between conspecifics for several characteristics, which include reproductive status, hierarchical rank, familiarity, group membership, kinship and individual identity (Thom \& Hurst 2004).

In class-level recognition, conspecifics are assigned to the appropriate class by using a relatively simple distinction between limited alternatives, such as 'male' versus 'female', 'familiar' versus 'unfamiliar', 'group member' versus 'nongroup member'. Signals that are relatively uniform for individuals within a class, but

\footnotetext{
* Correspondence: D. Baracchi, Università degli Studi di Firenze, Dipartimento di Biologia Evoluzionistica 'Leo Pardi’, Via Romana 17, 50125 Firenze, Italy.

E-mail address: david.baracchi@gmail.com (D. Baracchi).
}

relatively distinct from the overall population, are usually involved in these processes (Tibbetts \& Dale 2007). For individual recognition the evaluator learns the individually distinctive characteristics of the cue-bearer, which are predicted to be (1) variable enough to allow accurate discrimination between individuals and (2) not dependent on health (Dale et al. 2001). In contrast to identity signals, quality signals require high, differential costs to maintain an honest association with true quality (Zahavi 1975; Getty 2006). Unlike most sexual signals, which have production-related costs, several fighting ability signals have only social costs associated with their maintenance (Rohwer 1975; Maynard Smith \& Harper 1988; Senar 1999, 2006; Gil \& Gahr 2002; Whiting et al. 2003; Tibbetts \& Dale 2004). These 'area' signals are often termed 'conventional' or 'badges of status' (Guilford \& Dawkins 1995). Recent studies suggest that rank markings must be costly to their bearers because only high-quality individuals can support the social costs of increased aggression from other individuals (reviewed in Jawor \& Breitwisch 2003).

Both recognition and conventional signals are common in the animal kingdom and they occur in many different modalities, including olfactory, visual and acoustic (reviewed in Dale et al. 2001). Several studies have shown that visual signals evolved as badges of status or recognition cues in many vertebrates (reviewed in Senar 
1999; Whiting et al. 2003; Setchell \& Wickings 2005). Furthermore, even if invertebrates, and in particular social insects, primarily use chemical cues for communication (reviewed in Vander Meer et al. 1998; Howard \& Blomquist 2005) both observational and experimental evidence has shown that they are also able to use the visual channel (Shreeve 1987; Karavanich \& Atema 1998; Beani \& Turillazzi 1999; Tibbetts 2002; Tibbetts \& Dale 2004). The paper wasps Polistes fuscatus and Polistes dominulus have variable cuticular markings that are used for social communication. Despite their similarities, the signals of these two species apparently convey completely different information. Experiments in which facial and abdominal markings of $P$. fuscatus females were manipulated suggest that workers and gynes use these features to recognize individual nestmates (Tibbetts 2002). In contrast, according to Tibbetts \& Dale (2004) the complexity (brokenness) of facial markings of $P$. dominulus females in a North American population conveys information on their agonistic qualities. Tibbetts \& Dale (2004) suggested that the cost of this badge is not due to pigment production, since it represents only $1 \%$ of the total body pigment, but to the social costs that it entails. In contrast, this badge of status is absent in the nesting foundresses of an Italian population (Cervo et al. 2008). Furthermore, although Zanette \& Field (2009) did report a correlation between facial markings and dominance in a Spanish population, this was no longer significant when other factors (e.g. intragroup relatedness) were also considered. In this case the hypothesis is that badges of status are one of various factors that can influence dominance hierarchies and reproductive skew (Zanette \& Field 2009). Owing to the differences between these populations, many controversies in the literature revolve around the role of visual signals in wasps (see Strassmann 2004; Cervo et al. 2008). Information on visual communication is also available for other genera not closely related to Polistes wasps. For example, a status signal was described and studied by Beani \& Turillazzi (1999) in males of Parischnogaster mellyi (Vespidae, Stenogastrinae), which use it during flying duels for winning a perch in aerial leks. Beani \& Turillazzi (1999) found that males were increasingly challenged by contenders when given an extra visual signal represented by an additional white stripe painted on the back of their gasters.

The Stenogastrinae, or hover wasps, represent a taxon of 58 described species in seven genera inhabiting the forests of South-East Asia (Turillazzi 1991; Carpenter \& Kojima 1996). They have small colonies (maximum 10 females) in which recognition, up to the individual level, might be useful for social organization. In the genera Liostenogaster, Eustenogaster and Parischnogaster various species present highly variable facial markings, potentially allowing the use of visual cues. Both Liostenogaster vechti and Liostenogaster flavolineata (two of the most common species) have a peculiar nesting biology with many colonies forming large aggregations, sometimes with hundreds of nests built within $5 \mathrm{~cm}$ of one other. As a consequence, colonies in clusters experience continuous landing attempts by neighbouring, alien individuals, which are sometimes received peacefully (Samuel 1987; Turillazzi et al. 1997; Coster-Longman 1998). Zanetti et al. (2001) observed how the hesitant approaching flights of landing individuals can elicit an alarm reaction from the residents of colonies of Parischnogaster striatula, just before recognition based on chemical cues could trigger aggressive reactions. These reports suggest a possible involvement of facial markings in the recognition process in both $L$. vechti and $L$. flavolineata.

The aim of our study was to determine whether visual communication could be important in the social organization of $L$. flavolineata and $L$. vechti. We first measured the head width (a reliable indicator of body size) and size of facial markings of female wasps collected in the field, checking for a relation of these features with ovarian development and social rank. Based on the results obtained in the first part of the study we tested whether (1) L. vechti females use their facial markings as quality signals to assess the value of conspecifics, and (2) L. flavolineata females are able to use facial markings of nestmates as visual recognition cues.

\section{METHODS}

\section{Studied Species}

Liostenogaster vechti forms colonies with up to seven females on a bracket-like or ringed nest (Turillazzi 1990). Colonies of this species are usually found in large clusters (up to more than 600 nests) on the walls of buildings, caves or overhanging rocks. For this species, Cervo et al. (1996) reported a nestmate recognition ability based on chemical cues, and Turillazzi (1990) found that, only one or two potentially egg-laying females per nest are usually present.

Liostenogaster flavolineata is one of the best-known species in the group. It builds mud comb nests with up to more than 100 cells, sometimes in huge aggregates (Hansell 1982; Samuel 1987). Similarly to $L$. vechti, chemical nestmate recognition in this species has been reported and studied by Cervo et al. (1996, 2002). Social groups are relatively small (up to 10 females) and newly emerged females may disperse or become helpers on their natal nests. Bridge (2005) and Bridge \& Field (2007) reported the existence of a queue for dominance based on gerontocracy (dominance order is age-based: in a nest a subordinate inherits dominance only when all her older relatives have disappeared). Field \& Foster (1999) and Sumner et al. (2002) found on average only one egg-laying female per nest and only $8 \%$ of nondominant females with developed ovaries.

\section{Sample Collection}

Twenty-five colonies of $L$. vechti with a total of 76 females (mean: 3.0 females per colony, range 2-5) and 30 colonies of L. flavolineata with a total of 97 females (mean: 3.2 females per colony, range 2-5) were collected from two different sites: Bukit Fraser (1000 $\mathrm{m}$ above sea level) and Genting Tea Estate $(610 \mathrm{~m}$ above sea level) in the Pahang State of Peninsular Malaysia. We killed all the wasps at $-20^{\circ} \mathrm{C}$ before measuring head width, ovarian development and facial markings (see below).

\section{Morphological Measurements and Facial Pattern Categorization}

We took a picture of the 'face' of each collected wasp with a Fujifilm digital camera (Fig. 1). A body size estimate was then obtained by measuring the maximum width of the head (Eickwort 1969). We dissected the ovaries of all females under a binocular microscope to determine their reproductive status. For each individual, the ovarian status was quantified by using an ovarian index (OI) based on the development of the ovaries. This was performed by taking a picture using a Fujifilm camera and by measuring the length of the six largest oocytes present in the ovarioles. Since usually only the dominant female lays eggs, she possesses the most developed ovaries in her colony. The OI is thus a meaningful rank estimator. We also checked the spermatheca of each female for the presence of sperm. To categorize the facial patterns of females in both species we measured the size of the brown pigmented area on the faces (facial marking size, FMS; see also Zanette \& Field 2009). All measurements were made on digital photographs by using the free software Image (http://rsbweb.nih.gov/ij/). We took into account only the area corresponding to the clypeus plus eyebrows (dorsal to the antennal sockets region) since it includes most of the variability in the wasps' facial markings. Inner and outer eye stripes, antennae and mandibles were ignored as they were yellow in all the specimens of both species (see Appendix Fig. A1). To avoid the bias from individuals with a high FMS but still too young to develop ovaries and reproduce, further statistical analyses were performed only for individuals 

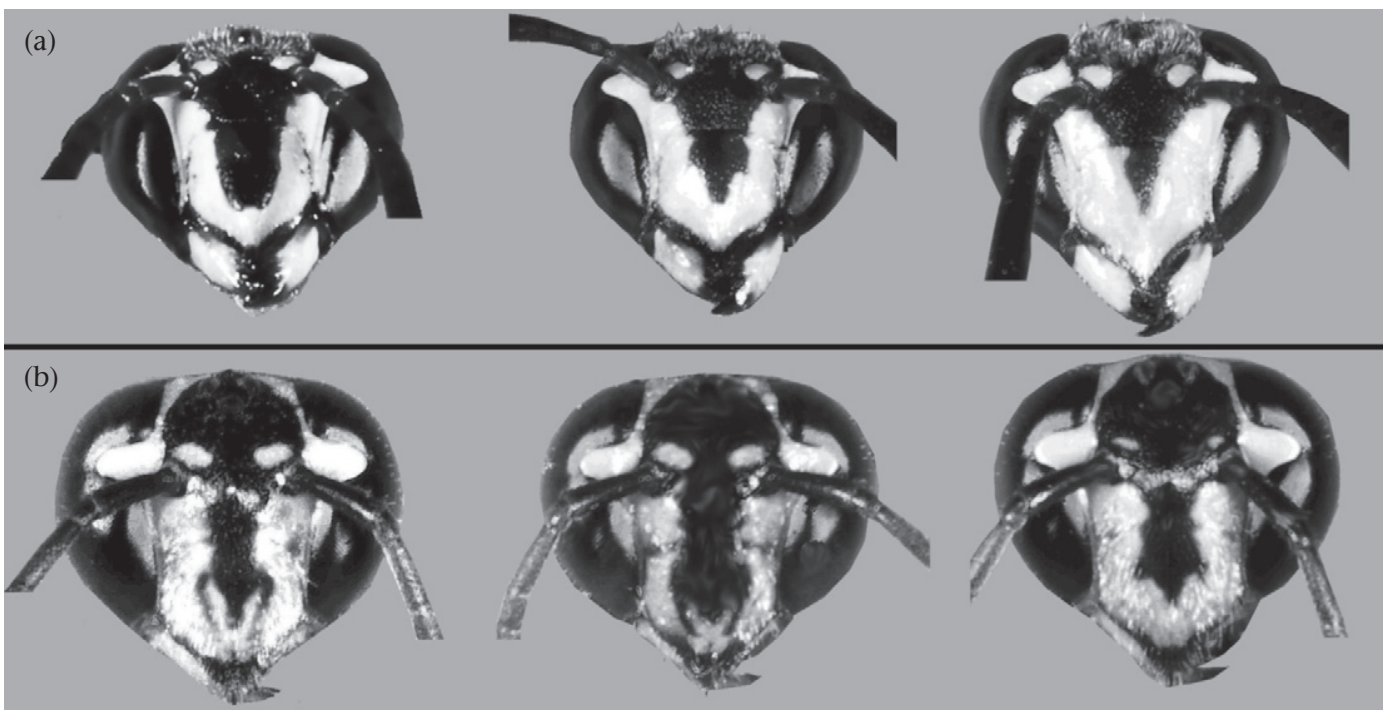

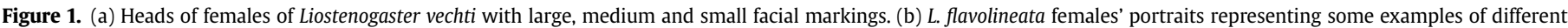
facial patterns present in the species.

showing an OI higher than 100 (L. vechti: $N=38$; L. flavolineata: $N=58$ ), which roughly corresponds, in both species, to the division value of the two curves of the OI distribution (see also Appendix Fig. A2a, b). ANOVA designs were used for comparing facial markings with physiological and morphological data. In the general linear model (GLM) analysis head width and FMS were used as covariate variables, colony as a random factor and $\mathrm{OI}$ as dependent variable. All analyses were performed using the statistical program SPSS 13.0 (SPSS Inc., Chicago, IL, U.S.A.) for Windows.

\section{Behavioural Assays}

On the basis of the absence of correlation between facial pattern and morphoanatomical measurements, we designed a specific behavioural experiment for each species. We tested whether L. vechti wasps use facial markings as signals to assess the quality of conspecifics and whether $L$. flavolineata wasps are able to use them as visual cues (i.e. to discriminate familiar from unfamiliar individuals). The experiments were carried out in the field on two nest clusters of $L$. flavolineata and on two clusters of $L$. vechti located at Genting Tea Estate and Bukit Fraser, always on sunny days between 1000 and 1800 hours.

\section{L. vechti}

We prepared several pairs of unfamiliar lures (consisting of female wasps taken from different clusters). Before trials, the wasps were killed by freezing and then rinsed in $500 \mu \mathrm{l}$ of pentane for $24 \mathrm{~h}$ to eliminate possible chemical cues. The lures were paired for comparable head width (Tibbetts 2002) but selected for different size of the brown facial marking (mean FMS of the paired lures: ca. 1900 and ca. 2500 area units, respectively). During the experiments we presented the two lures (for $1 \mathrm{~min}$ ) alternately and approximately $1 \mathrm{~h}$ apart to the nest residents of free-living colonies $(N=60)$ with a procedure similar to that followed by Cervo et al. (2002). We counted the interactions of the residents with the lures. To control for order effects, half of the colonies were first presented with the lures with a large brown area while the other half were first presented with the lures with a small brown area.

To verify that the brown facial marking of $L$. vechti is an actual visual stimulus for the wasps, we performed a test in which we presented a natural-size micropicture of a female face with five artificially increased levels of FMS edited with a picture manager software (range $1800-2600$, in steps of about 160) to the residents of 30 field colonies (see Appendix Fig. A3). A brown tag and a yellow tag of the same dimension as the wasp face were also shown to each colony to ascertain whether the face models triggered a larger or smaller reaction than a nonspecific stimulus. To control for order effects, the seven stimuli were presented in a random sequence.

\section{L. flavolineata}

Before the trials, two nondominant females (foraging females according to Samuel 1987) were collected from each experimental colony $(N=40)$ that had at least three wasps; they were killed by freezing and then rinsed in $500 \mu \mathrm{l}$ of pentane for $24 \mathrm{~h}$ to eliminate any possible chemical cues. We then applied an experimental protocol in which the facial markings of focal wasps were altered with paint, and control treatments in which focal wasps were painted without altering their markings (Tibbetts 2002). In the experimental treatments, the facial markings were changed either by adding brown paint (on average $1.6 \pm 0.5 \%$ of the brown area) to the yellow surface contiguous to the brown area $(N=20)$ and by adding yellow paint (on average $1.6 \pm 0.5 \%$ of the brown area) to the brown surface contiguous to the yellow area $(N=20)$. For the control, a similarsized brown area and a similar-sized yellow area of the wasps' face were painted with brown $(N=20)$ and yellow paint $(N=20)$, respectively. This design allowed us to test whether experimental responses were caused by alteration of the facial marking, and not by the covering of specific facial areas with paint (Tibbetts 2002). The two lures were presented alternately and approximately $1 \mathrm{~h}$ apart to the resident females. To control for order effects, half of the experimental treatments were performed before the controls.

During the experiments on both species we held the lure for $1 \mathrm{~min}$ at about $1-2 \mathrm{~cm}$ away from the nest, starting when at least one of the resident females showed signs of reaction. To avoid excessive disturbance, wasps of experimental colonies were not marked. The number of responses by all colony members was normalized for the number of females on the nest. For both species the reactions of resident females considered were antennation (nonaggressive reaction), bending of the abdomen (a behaviour related to alarm/defence of the nest) and bites towards the lure (aggressive reaction). Ambiguous behaviours were excluded from analyses to minimize subjectivity. All the experiments were 
videotaped and the videos were later analysed with a blind procedure. All the data were analysed with the Wilcoxon signedranks test: so that each colony was compared with its own reaction when facing the two different lures. For data evaluation in the 'photograph' complementary test conducted on L. vechti, we used a repeated measures ANOVA design (GLM for repeated measures), with the size of the brown facial markings as within-subject variables. As the data were not normally distributed and homogeneity of variances and sphericity could not be assumed in several cases, we performed corrections according to Huynh-Feldt epsilon. All

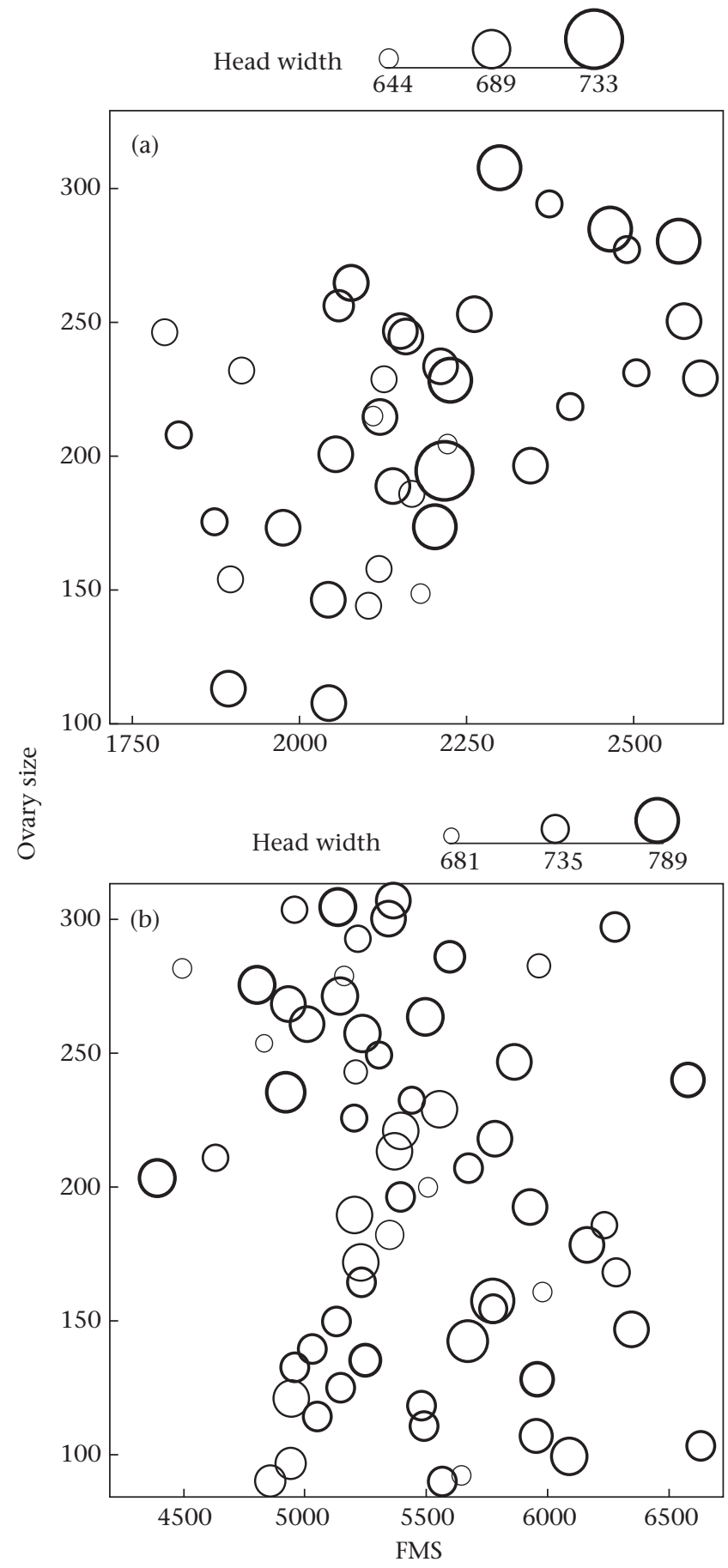

Figure 2. Correlations between ovary development (ovarian index, OI) and facial marking size (FMS, reported in area units) for different head widths (black dot size) in (a) L. vechti and (b) L. flavolineata females. analyses were performed using the statistical program SPSS 13.0 for Windows.

\section{RESULTS}

Head Width, Ovarian Development and Visual Markings

\section{L. vechti}

Head width and FMS were normally distributed in the population (Kolmogorov-Smirnov test: $Z=0.43, N=76, P=0.98$; $Z=0.54, N=76, P=0.93$, respectively) and correlated with each other (Pearson correlation: $r_{75}=0.26, P=0.023$ ). By contrast, the distribution of $\mathrm{OI}$ in the overall population was evidently bimodal with a clear cut around value 100 (area units; see Appendix Fig. A2a); all the unfertilized females $(N=24)$ and $25 \%$ of fertilized females (13 of 51) had an OI below this level.

When we examined individuals with an OI higher than 100, the GLM analysis found a significant relationship of ovarian development with the FMS $\left(F_{1,12}=7.538, N=38, P=0.002\right)$ and weakly also with head width $\left(F_{1,12}=4.095, N=38, P=0.044\right.$; Fig. 2a). The colony membership, entered as a random factor into the model, had no significant relevance $\left(F_{23,12}=1.137, N=38, P=0.422\right)$. These results indicate that in the overall population as well as within any colony the

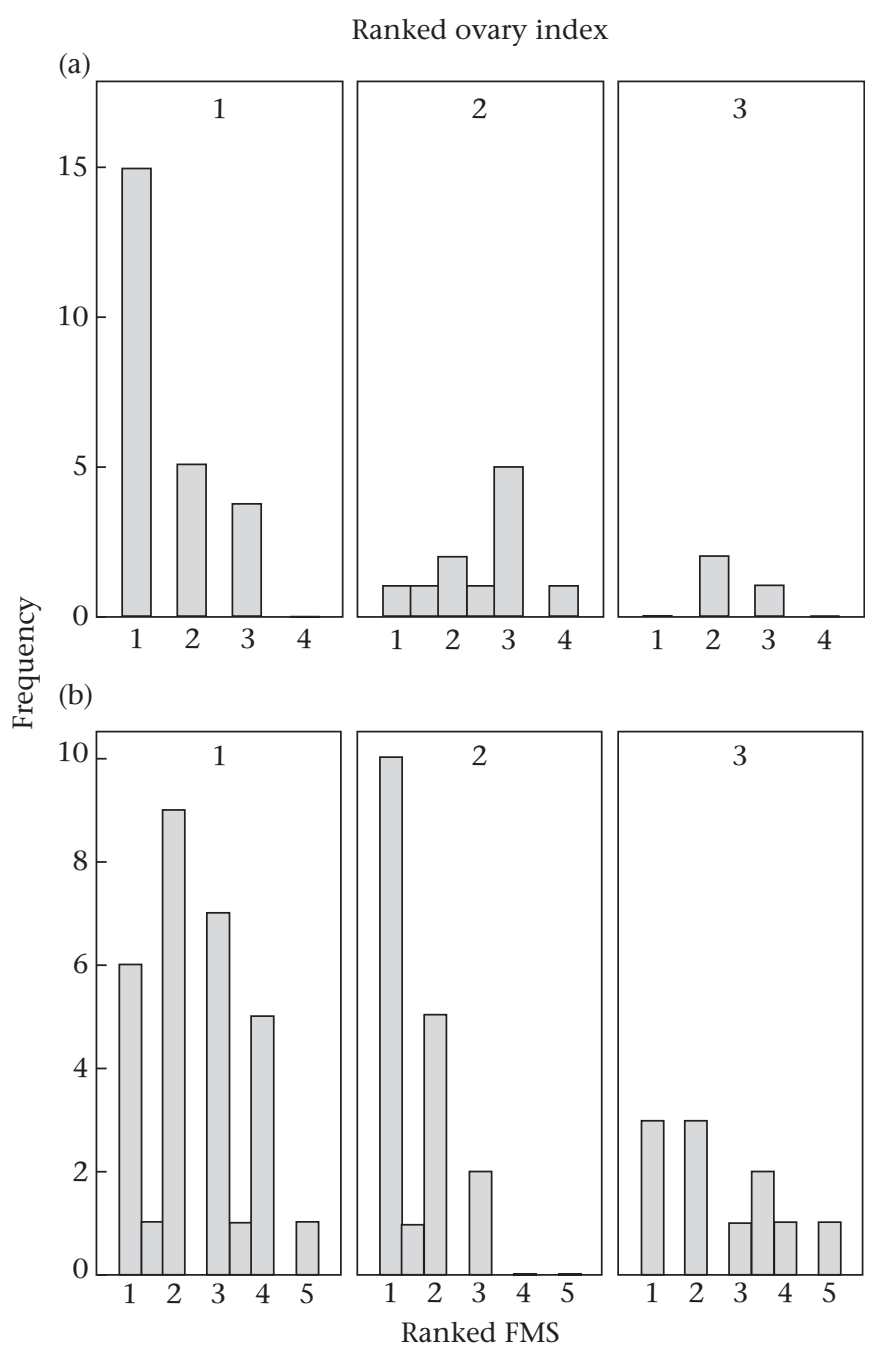

Figure 3. (a) Females of $L$. vechti $(N=38)$ ranked for ovarian index and FMS (i.e. the FMS decreases from 1 to 4$)$ in each of the colonies examined $(N=25)$. (b) Females of L. flavolineata $(N=58)$ ranked for ovarian index and FMS in each of the colonies examined $(N=30)$. 

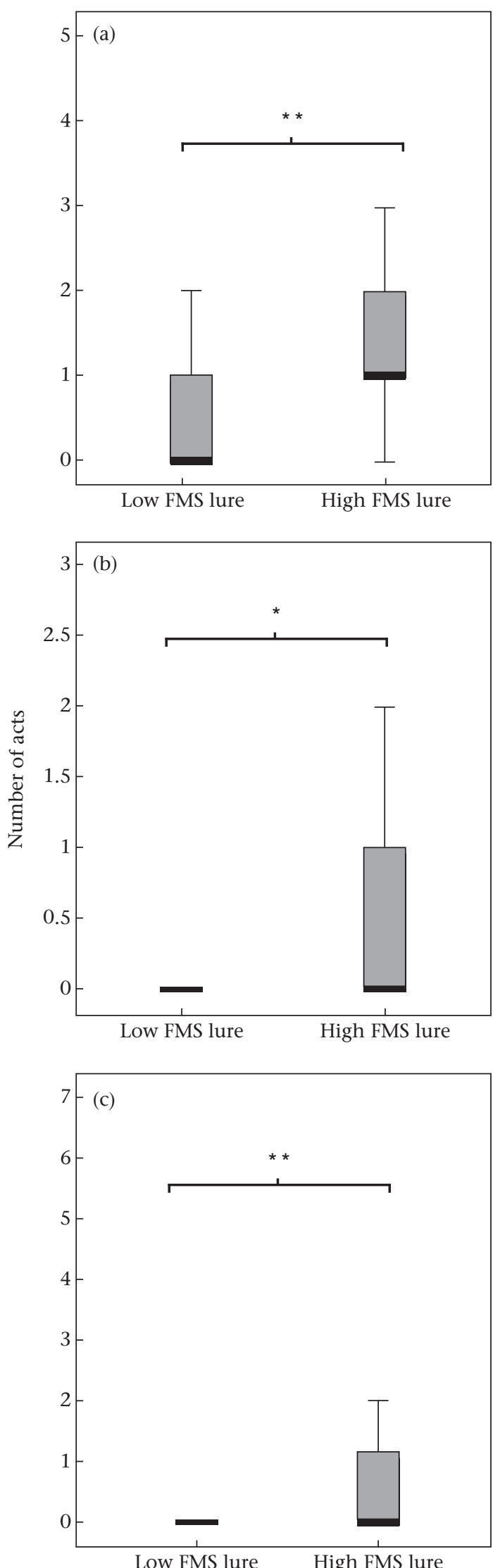

Figure 4. Comparison between the number of (a) abdominal bends, (b) antennations and (c) bites directed by $L$. vechti resident females against low FMS and high FMS lures. Box plots show medians, 25th and 75th percentiles. ${ }^{*} P<0.001$; ${ }^{* *} P<0.0001$. individuals with the highest FMS, regardless of their body size (head width), were often the reproductively dominant ones. These results are also visualized in Fig. 3a which ranks the relative position of females for ovarian development and FMS values in each colony.

\section{L. flavolineata}

The distribution of $\mathrm{OI}$ in the overall population of females examined $(N=97)$ is given in Appendix Fig. A2b. The distribution is not so different from that of $L$. vechti with a cut around value 100; almost all the unfertilized females (34 of 39) and some of the fertilized females (three of 56) had an OI below this level (the spermathecae of two females were not found). Head width and FMS were normally distributed in the population (KolmogorovSmirnov test: $Z=0.57, N=97, P=0.89 ; Z=0.66, N=97, P=0.76$, respectively) and not correlated with each other (Pearson correlation: $\left.r_{96}=0.151, P=0.127\right)$. When we examined the individuals with OI higher than 100, the GLM found no significant relationship of the ovarian development with FMS $\left(F_{1,27}=1.562, N=58\right.$, $P=0.222)$ or with head width $\left(F_{1,27}=1.895, N=58, P=0.180\right.$; Fig. 2b). The colony membership, entered as a random factor into the model, had no significant relevance $\left(F_{28,27}=0.537, N=58\right.$, $P=0.946$; see also Fig. $3 \mathrm{~b}$, which ranks the relative position of females for ovarian development and FMS values in each colony).

To be sure to capture the variation in the facial markings adequately, additional parameters apart from the FMS area were measured. However, no significant correlation was found between these parameters and the ovarian development (see Appendix Fig. A4 legend). These results indicate that the reproductive status of a wasp is independent from its FMS value.

\section{Behavioural Assays}

L. vechti

On average, the lures with a larger FMS received significantly more inspections and aggression than the lures with a smaller FMS $(N=60$; Wilcoxon test: antennations: $Z=-3.13, P<0.001$; bites: $Z=-3.93, P<0.0001)$. Similarly, larger FMS lures triggered the bending of the abdomen much more than smaller FMS lures (Wilcoxon test: $Z=-4.65, N=60, P<0.0001$; Fig. 4).

When the micropictures of the wasps' faces were presented to the colonies, we observed that the larger the FMS value was, the

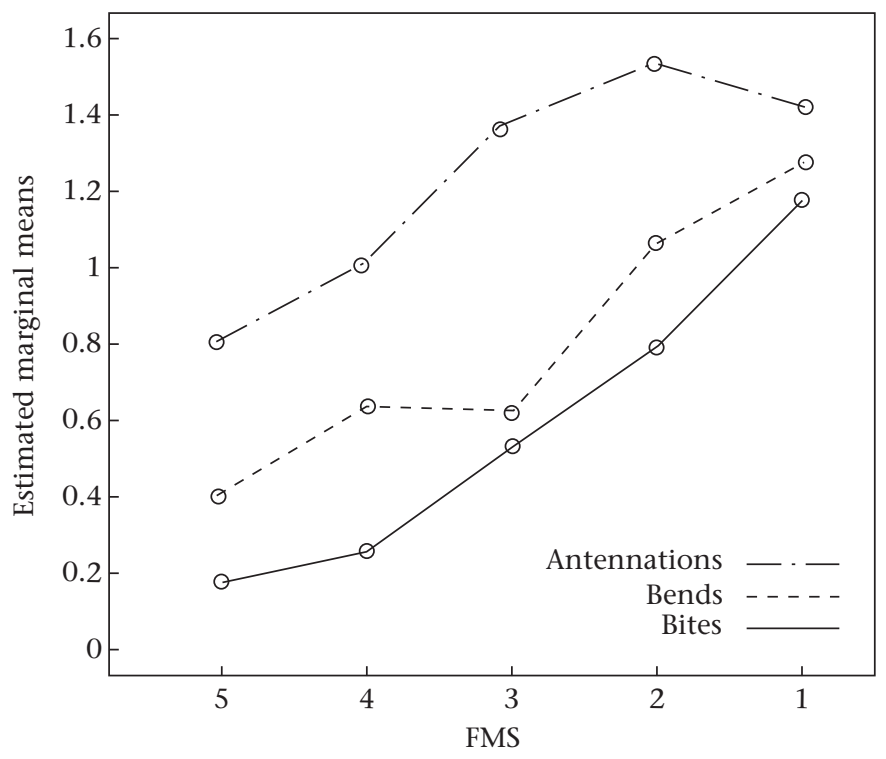

Figure 5. Explorative and aggressive responses elicited when the micropictures of the female faces with five increased levels of FMS were presented to $30 \mathrm{~L}$. vechti colonies. 

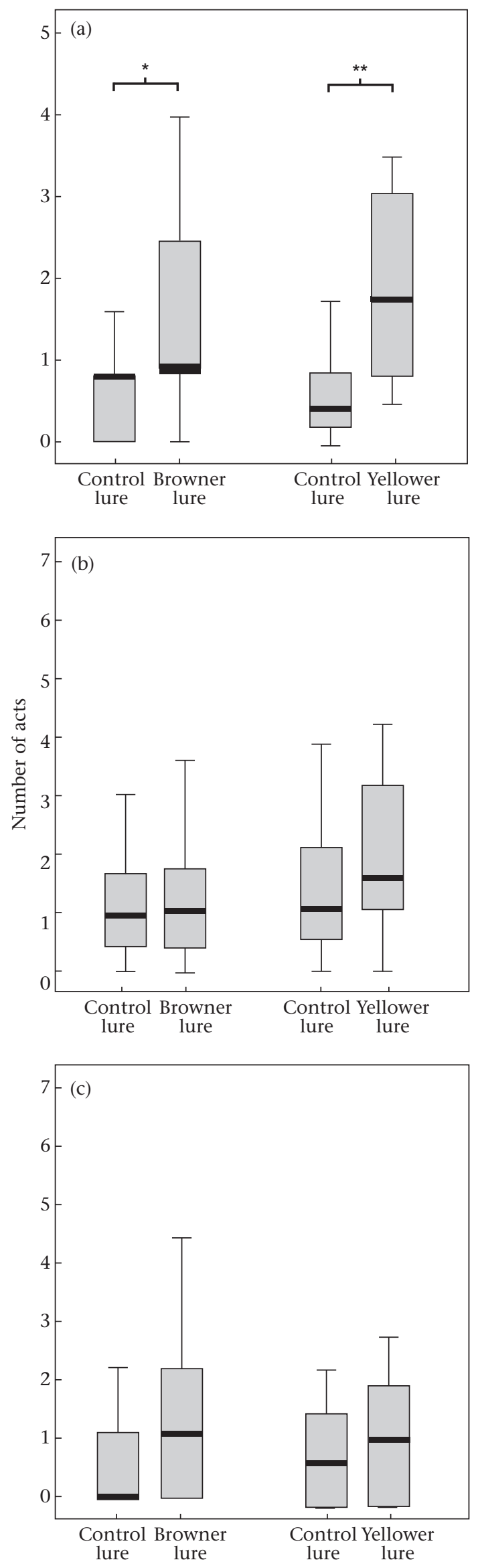

higher the elicited explorative and aggressive responses were (GLM for repeated measures corrected according to Huyn-Feldt's epsilon, $N=30$; antennations: $F_{4}=4.06, P=0.04$; abdomen bends: $F_{3.9}=8.96, P=0.001$; bites: $F_{2.9}=6.11, P=0.001$; Fig. 5 ). Contrarily, the reactions elicited by the brown and yellow tags were lower even than those elicited by the photograph of the face with the smaller FMS value $(N=30$; Wilcoxon test: yellow tag: $Z=3.38$, $P<0.001$; brown tag: $Z=3.73, P<0.001$ ). These results indicate that the levels of aggression of the residents of the tested colonies increased with the proportion of brown pigment on the face of the experimentally presented wasp. This also suggests that a wasp with a browner face should represent a greater threat for the dominance order of the colony than a wasp with a yellower face.

\section{L. flavolineata}

Neither browner nor yellower experimental lures elicited significantly more antennations and bites than the controls $(N=20$; Wilcoxon test: browner lures: antennations: $Z=-0.08$, $P=0.94$; bites: $Z=-0.846, P=0.46$; yellower lures: antennations: $Z=-1.77, P=0.079$; bites: $Z=-1.34, P=0.17$; Fig. 6 ). However, the number of abdomen bends triggered by the experimental lures was significantly higher than that triggered by the controls both when brown (Wilcoxon test: $Z=-2.65, N=20$, $P<0.006$ ) and when yellow (Wilcoxon test: $Z=-3.24, N=20$, $P<0.0001)$. These results indicate that the residents of the tested colonies were alarmed by a wasp that was unfamiliar owing to altered (increased and diminished) facial markings.

\section{DISCUSSION}

In $P$. dominulus, a temperate wasp species, body size is a significant, although not absolute, predictor of rank in associative foundations, probably because it confers some competitive ability (Turillazzi \& Pardi 1977; Reeve 1991; Cervo et al. 2008; Zanette \& Field 2009). In hover wasps, mainly because of the relatively aseasonal tropical environment and complete absence of caste dimorphism, the range of body size of individuals is less pronounced than in temperate Polistes wasps. As a consequence, the fighting ability of females may be less influenced by body size. This difference can account for our results: a weak influence of body size (head width) in the dominance hierarchy of $L$. vechti and no influence in that of $L$. flavolineata. Our behavioural experiments showed that the variable brown facial pattern functions as a visual signal in these two Stenogastrinae species. Dissections and measurements provided evidence that these visual signals can convey different information in the two species.

In $L$. vechti the size of the brown facial markings was correlated with head width and was a more important predictor of ovarian development than body size. Furthermore, it was a decisive element in rank determination and was used as a status badge by wasp females. In a colony, individuals had larger facial markings the bigger their ovaries. These findings suggest that individuals choosing different strategies (e.g. to stay in their native nest or migrate) may lead to a redistribution of dominants and subordinates among nests of their own or neighbouring clusters. In fact, in this species individuals have a strong tendency to shift between different nests (Coster-Longman 1998). Several females leave their nests to join other colonies or become floaters as happens in L. flavolineata (Samuel 1987; Field et al. 1998). Cervo et al. (1996, 2002) demonstrated nestmate recognition ability in $L$. vechti as well as in L. flavolineata; this ability allows residents to discriminate conspecifics from alien colonies. However, Cervo et al. (1996, 2002)

Figure 6. Comparison between the number of (a) abdominal bends, (b) antennations and (c) bites directed by L. flavolineata resident females towards experimental and control lures. Box plots show medians, 25 th and 75 th percentiles. ${ }^{*} P<0.006$; ${ }^{* *} P<0.0001$. 
also noted a high percentage of 'erroneous' acceptances of alien females in both $L$. vechti (24\%) and L. flavolineata (30\%), and hypothesized that the discrimination ability in clustering species might be lower than in other hover wasps (e.g. Parischnogaster jacobsoni, Cervo et al. 2002). However, if not all alien females represent a real threat for a colony because not all of them will try to reproduce, their acceptance could be not an 'error' but a choice based on visual cues. This could account for the significant number of alien females that are peacefully received on the nests by resident females (Samuel 1987; Turillazzi et al. 1997; Coster-Longman 1998). In our study, aggression was observed towards high-ranking and not towards lower-ranking experimentally presented individuals. This behaviour allows resident females to reduce the costs of continuously rejecting alien nonfertile individuals approaching or landing on their nest, at the same time maintaining an efficient control system. Floaters and alien females, on the other hand, often approach alien nests with uncertain and explorative flight (Turillazzi 1990) and status signalling by facial marking may help these wasps to present themselves to alien colonies, testing the immediate response of residents and exploring the possibility of joining or not in relation to the level of aggression received.

Independent nesting is very unsuccessful in these wasps (in L. flavolineata, for example, more than $50 \%$ of the single female foundations fail: Samuel 1987; Field et al. 1998). Thus, a female is better off if it has help in brood rearing. A female with large facial markings (high status badge) may incur two sources of social costs: it is challenged when it tries to join an alien colony and, if it founds a nest alone, it may be less likely to be joined by other potential helper individuals.

The fact that wasps with higher status badges were subjected to more aggression by alien females could appear counterintuitive. Signals of agonistic ability are expected to reduce the cost of aggressive conflicts by allowing opponents to avoid costly fights that have predictable outcomes (Senar 2006). However, attacked individuals are never predicted to give up immediately when competing over something as valuable as their nest. Furthermore, our result makes more sense if we consider that signals of fighting ability will remain evolutionarily stable and exempt from cheating only if receivers of signals aggressively 'test' the sender's true behavioural status (Rohwer 1977). Receivers may test signal accuracy mainly during landings of potentially threatening alien wasps (i.e. an egg-layer female), but accept the signal without continuous aggressiveness in a linear hierarchy inside the colony (and this also represents a benefit that balances the high social costs, in aggression, suffered at the beginning by the bearer of a higher status badge). Maynard Smith \& Harper (1988) suggested a similar scenario in a nonsocial contest and Tibbetts et al. (2010) demonstrated that in $P$. dominulus wasps the receiver's responses to signals of agonistic ability are context dependent.

A different situation occurs in $L$. flavolineata where the visual signal could convey completely different information. No relationships were found between the size of facial markings and body size (head width) or ovarian development, either in the overall sample or within single colonies. Consequently, we exclude the existence of visual cues as quality signals in this species. The lack of status badges in L. flavolineata is consistent with the existence of dominance hierarchies based on gerontocracy in which dominance order is agebased (Bridge 2005; Bridge \& Field 2007). Even if all helpers have the potential to become egg-layers (Field \& Foster 1999), only the highest quality individuals, and thus the most likely to survive long enough to inherit, are effectively selected to be dominants by queuing (Field et al. 1998). Still, our behavioural experiment indicates that resident wasps respond with an alarm/defence posture (bending) towards nestmates whose facial markings have been experimentally altered, suggesting that $L$. flavolineata wasps use the visual channel for communication and discriminate between familiar and unfamiliar individuals. Visual cues in this species could represent an additional useful recognition tool because nests often occur in very dense clusters. Beyond the use of visual signals for recognition of familiar individuals, one potential benefit of visual signals in L. flavolineata might be the reduction of aggression among nestmates. If facial markings can be learned as an individually distinctive characteristic, they may permit an accurate discrimination of individuals on the nest, allowing newly emerged wasps to recognize each nestmate as an individual and learn and memorize its position in the dominance queue (Bridge \& Field 2007). This could help a subordinate individual to assess the length of the queue and to decide whether to leave or to remain on the natal nest. Unfortunately, as often occurs, it is very difficult to distinguish between true individual recognition (where the receiver learns the signaller's individually distinctive characteristics and associates them with the signaller itself) and class-level recognition (where the learned signaller's distinctive characteristics are associated with the inferred classspecific information about the signaller; Sherman et al. 1997; Tibbetts \& Dale 2007). In both cases, wasps learn the individually distinctive facial pattern of the signaller. Our behavioural experiments did not allow us to discriminate between these two kinds of recognition and further research is needed to clarify this aspect of the hover wasps' biology. In conclusion, our results show the relevance of visual communication in both these species of hover wasps. The size of the dark facial markings of female $L$. vechti is related to reproductive dominance and represents a badge of status. On the other hand, $L$. flavolineata use facial markings as visual recognition cues. Our results on two different species of stenogastrine wasps suggest that communication systems based on visual recognition cues might be a primitive feature of the genus. Moreover, our study reveals that visual communication might be widespread among the Vespidae and other social insects, and that similar selection pressures might have produced similar communication systems in two distinct wasp subfamilies, the Polistinae and Stenogastrinae.

\section{Acknowledgments}

We thank Dr Leonardo Dapporto, Dr Rita Cervo (Università di Firenze, Italy) and Professor Jeremy Field (University of Sussex, U.K.) for critically reading and improving the manuscript and the anonymous referees for their helpful comments. We also thank Professor Rosly Bin Hashim (University of Malaya, Malaysia), Mr Henry Barlow and $\mathrm{Mr}$ Simon Hok for their support in Malaysia. We thank also Professor Roscoe Stanyon for revising the English text. This research was funded by the Università degli Studi di Firenze.

\section{References}

Beani, L. \& Turillazzi, S. 1999. Stripes display in hover wasps (Vespidae-Stenogastrinae): a socially costly status badge. Animal Behaviour, 57, 1233-1239.

Bridge, C. A. L. 2005. Rank and inheritance in a facultative eusocial hover wasp. Ph.D thesis, University College London.

Bridge, W. \& Field, J. 2007. Queuing for dominance: gerontocracy and queuejumping in the hover wasp Liostenogaster flavolineata. Behavioral Ecology and Sociobiology, 6, 1253-1259.

Carpenter, J. M. \& Kojima, J. 1996. Checklist of the species in the subfamily Stenogastrinae (Hymenoptera: Vespidae). Journal of the New York Entomological Society, 104, 21-36.

Cervo, R., Dani, F. R. \& Turillazzi, S. 1996. Nestmate recognition in three species of stenogastrine wasps (Hymenoptera: Vespidae). Behavioral Ecology and Sociobiology, 39, 311-316.

Cervo, R., Dani, F. R. \& Zanetti, P. 2002. Chemical nestmate recognition in a stenogastrine wasp, Liostenogaster flavolineata (Hymenoptera Vespidae). Ethology Ecology and Evolution, 14, 351-363.

Cervo, R., Dapporto, L., Beani, L., Strassmann, J. E. \& Turillazzi, S. 2008. On status badges and quality signals in the paper wasp Polistes dominulus: body size, facial colour patterns and hierarchical rank. Proceedings of the Royal Society B, 275, 1189-1196. 
Coster-Longman, C. 1998. Ecological factors in the agglomeration and evolution of sociality in the Stenogastrinae (Hymenoptera; Vespidae). Ph.D. thesis, Università degli Studi di Firenze.

Dale, J., Lank, D. B. \& Reeve, H. K. 2001. Signaling individual identity versus quality: a model and case studies with ruffs, queleas, and house finches. American Naturalist, 158, 75-86.

Eickwort, K. 1969. Separation of the caste of Polistes exclamans and notes on its biology (Hymenoptera: Vespidae). Insectes Sociaux, 16, 67-72.

Field, J. \& Foster, W. 1999. Helping behaviour in facultatively eusocial hover wasps: an experimental test of the subfertility hypothesis. Animal Behaviour, 57, 633-636.

Field, J., Foster, W., Shreeves, G. \& Sumner, S. 1998. Ecological constraints on independent nesting in facultatively eusocial hover wasps. Proceedings of the Royal Society B, 265, 973-977.

Getty, T. 2006. Sexually selected signals are not similar to sports handicaps. Trends in Ecology \& Evolution, 21, 83-88.

Gil, D. \& Gahr, M. 2002. The honesty of bird song: multiple constraints for multiple traits. Trends in Ecology \& Evolution, 17, 133-141.

Guilford, T. \& Dawkins, M. S. 1995. What are conventional signals? Animal Behaviour, 49, 1689-1695.

Hansell, M. H. 1982. Colony membership in the wasp Parischnogaster striatula (Stenogastrinae). Animal Behaviour, 30, 1258-1259.

Hölldobler, B. \& Wilson, E. O. 1990. The Ants. Cambridge, Massachusetts: Harvard University Press, Belknap Press.

Howard, R. W. \& Blomquist, G. J. 2005. Ecological, behavioral, and biochemical aspects of insect hydrocarbons. Annual Review of Entomology, 50, 371-393.

Jawor, J. M. \& Breitwisch, R. 2003. Melanin ornaments, honesty, and sexual selection. Auk, 120, 249-265.

Karavanich, C. \& Atema, J. 1998. Individual recognition and memory in lobster dominance. Animal Behaviour, 56, 1553-1560.

Maynard Smith, J. \& Harper, D. 1988. Animal Signals. Oxford: Oxford University Press

Reeve, H. K. 1991. Polistes. In: The Social Biology of Wasps (Ed. by K. G. Ross \& R. W. Matthews), pp. 99-148. Ithaca, NY: Cornell University Press.

Rohwer, S. 1975 . The social significance of avian winter plumage variability. Evolution, 29, 593-610.

Rohwer, S. 1977. Status signalling in Harris' sparrows. Behaviour, 61, 107-129.

Samuel, C. T. 1987. Factors affecting colony size in the stenogastrine wasp Liostenogaster flavolineata. Ph.D. thesis, University of Malaya, Kuala Lumpur.

Senar, J. C. 1999. Plumage colouration as a signal of social status. Proceedings of the International Ornithological Congress, 22, 1669-1686.

Senar, J. C. 2006. Color displays as intrasexual signals of aggression and dominance. In: Bird Coloration Function and Evolution. Vol. 2 (Ed. by G. E. Hill \& K. McGraw) pp. 87-136. London: Harvard University Press.

Setchell, J. M. \& Wickings, E. J. 2005. Dominance, status signals and coloration in mandrills (Mandrillus sphinx). Ethology, 111, 25-50.
Sherman, P. W., Reeve, H. K. \& Pfennig, D. W. 1997. Recognition systems. In: Behavioural Ecology: An Evolutionary Approach (Ed. by J. R. Krebs \& N. B. Davies) pp. 69-96. Oxford: Blackwell Science.

Shreeve, T. G. 1987. The mate location behaviour of the male speckled wood butterfly, Pararge aegeria, and the effect of phenotypic differences in hind-wing spotting. Animal Behaviour, 35, 682-690.

Strassmann, J. E. 2004. Rank crime and punishment. Nature, 432, 160-161.

Sumner, S., Casiraghi, M., Foster, W. \& Field, J. 2002. High reproductive skew in tropical hover wasps. Proceedings of the Royal Society B, 269, 179-186.

Tibbetts, E. A. 2002. Visual signals of individual identity in the paper wasp Polistes fuscatus. Proceedings of the Royal Society B, 269, 1423-1428.

Tibbetts, E. A. \& Dale, J. 2004. A socially enforced signal of quality in paper wasp. Nature, 432, 218-222.

Tibbetts, E. A. \& Dale, J. 2007. Individual recognition: it is good to be different. Trends in Ecology \& Evolution, 22, 529-537.

Tibbetts, E. A., Mettler, A. \& Levy, S. 2010. Mutual assessment via visual status signals in Polistes dominulus wasps. Biology Letters, 6, 10-13.

Thom, M. D. \& Hurst, J. L. 2004. Individual recognition by scent. Annales Zoologici Fennici, 41, 765-787.

Turillazzi, S. 1990. Social biology of Liostenogaster vechti Turillazzi (Hymenoptera Stenogastrinae). Tropical Zoology, 3, 69-87.

Turillazzi, S. 1991. The Stenogastrinae. In: The Social Biology of Wasps (Ed. by K. Ross \& R. Matthews), pp. 74-98. Ithaca, NY: Cornell University Press.

Turillazzi, S. \& Pardi, L. 1977. Body size and hierarchy in polygynic nests of Polistes gallicus (L.) (Hymenoptera, Vespidae). Monitore Zoologico Italiano, 11, 101-112.

Turillazzi, S., Cervo, R. \& Dani, F. R. 1997. Intra- and inter-specific relationships in a cluster of Stenogastrine wasp colonies (Hymenoptera; Vespidae). Ethology Ecology and Evolution, 9, 385-395.

Vander Meer, R. K., Breed, M. D., Espelie, K. E. \& Winston, M. L. (Eds). 1998 Pheromone Communication in Social Insects: Ants, Wasps, Bees and Termites. Boulder, Colorado: Westview.

Whiting, M. J., Nagy, K. \& Bateman, P. W. 2003. Evolution and maintenance of social status-signaling badges: experimental manipulations in lizards. In: Lizard Social Behavior (Ed. by S. F. Fox, J. K. McCoy \& T. A. Baird), pp. 47-82. Baltimore, Maryland: Johns Hopkins University Press.

Zahavi, A. 1975. Mate selection: a selection for a handicap. Journal of Theoretical Biology, 53, 205-213.

Zanette, L. \& Field, J. 2009. Cues, concessions, and inheritance: dominance hier archies in the paper wasp Polistes dominulus. Behavioral Ecology, 773-780.

Zanetti, P., Dani, F. R., Destri, S., Fanelli, D., Massolo, A., Moneti, G., Pieraccini, G. \& Turillazzi, S. 2001. Nestmate recognition in Parischnogaster striatula (Hymenoptera Stenogastrinae), visual and olfactory recognition cues. Journal of Insect Physiology, 47, 1013-1020.

\section{Appendix}

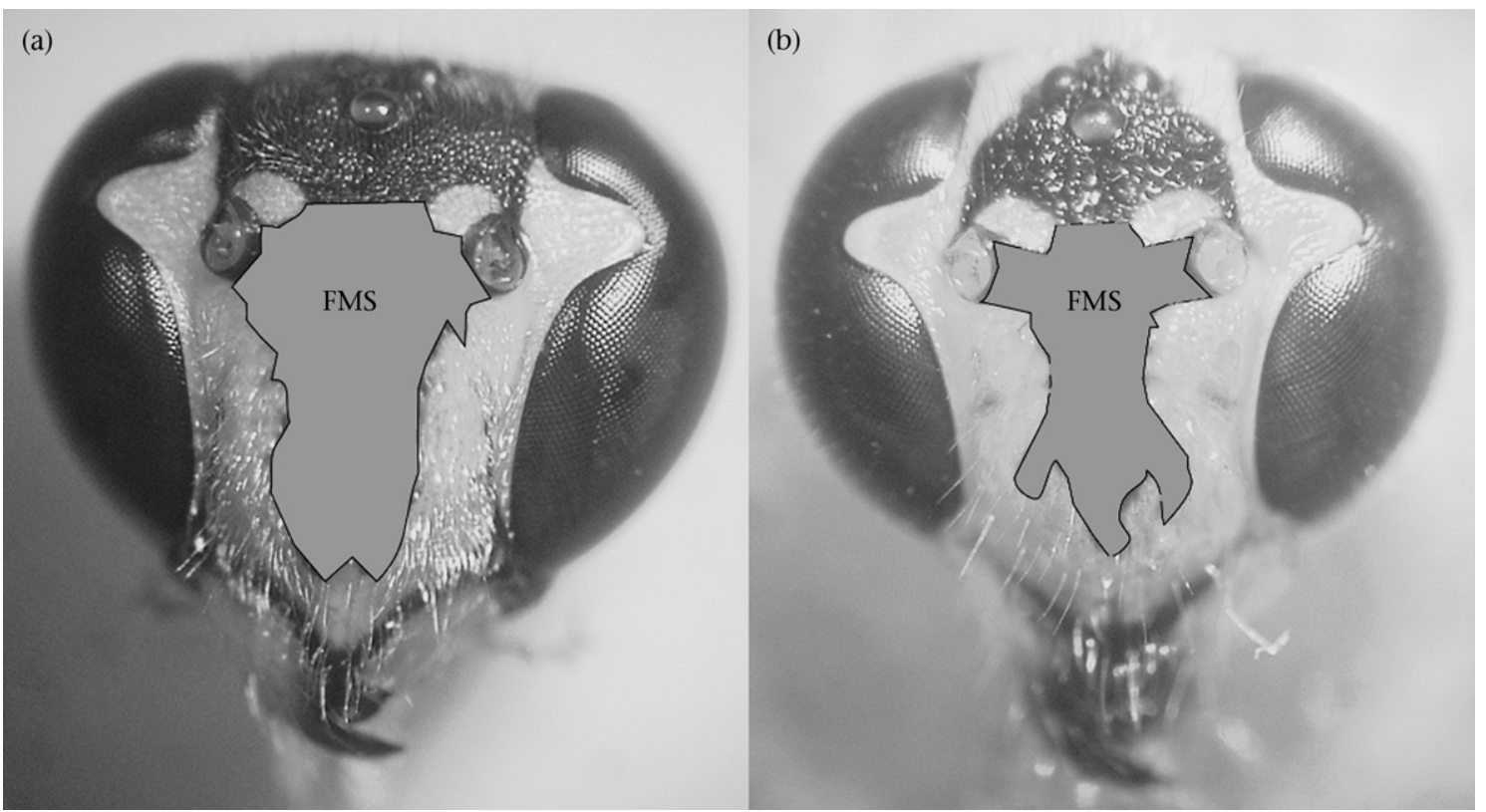

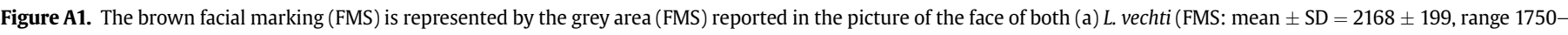
2600 area units) and (b) L. flavolineata (FMS: mean $\pm S D=53683 \pm 4951$ area units, range 4000-66 500) females. 


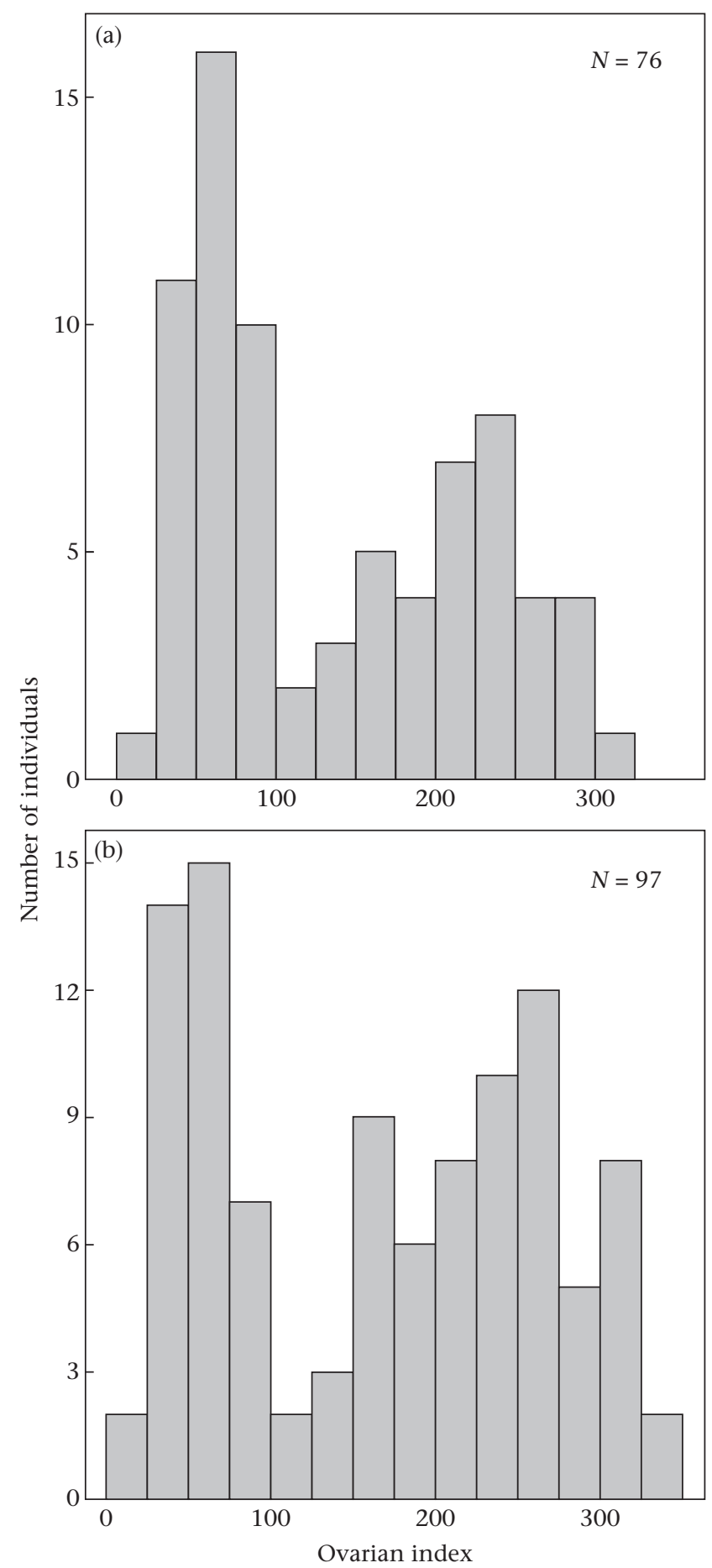

Figure A2. Distributions of ovarian index in the overall sampled population of (a) L. vechti females and (b) L. flavolineata females. 


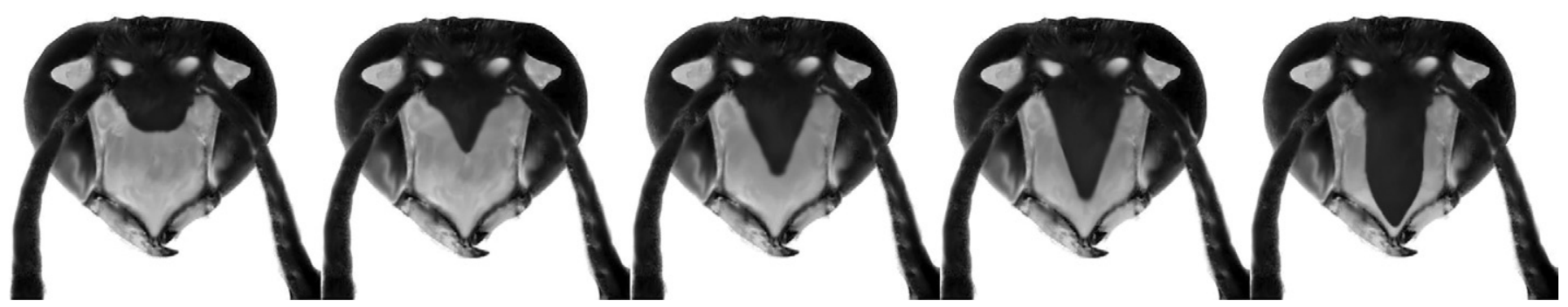

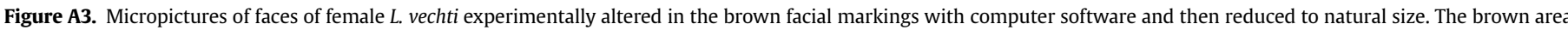

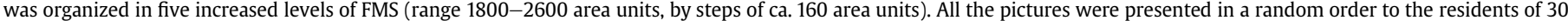
field colonies.

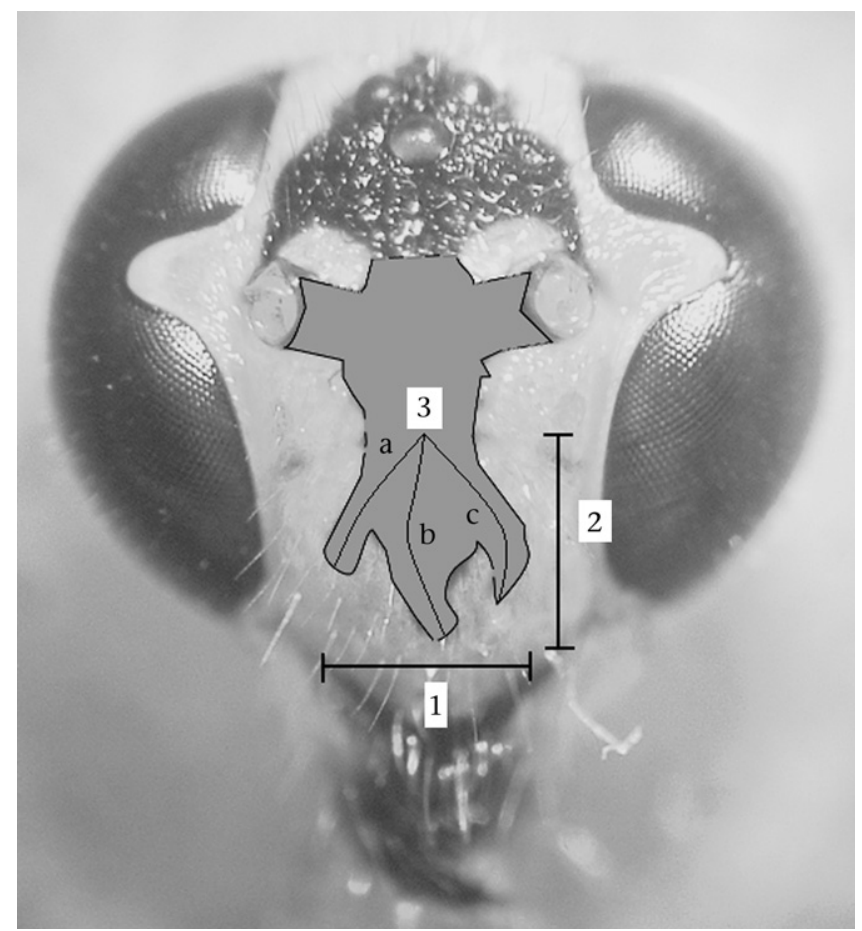

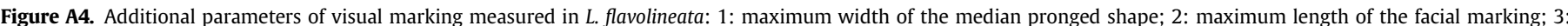

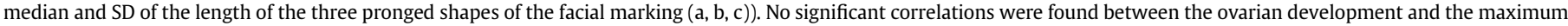

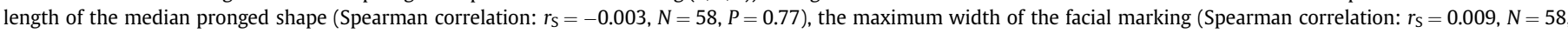

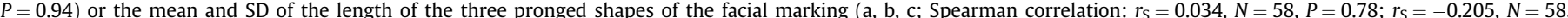

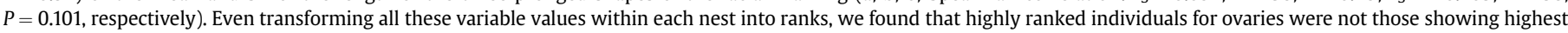

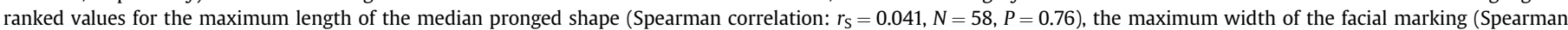

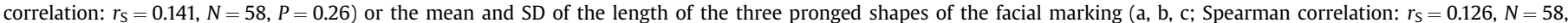
$P=0.32 ; r_{\mathrm{S}}=-0.175, N=58, P=0.16$, respectively). 